\title{
THE RESULTS OF A COMPARATIVE ANALYSIS OF THE POPULATION OF THE POPULATION OF UKRAINE AND COUNTRIES OF THE EUROPEAN REGION FOR HIV AS A RATIONALE FOR IMPROVING THE PHARMACEUTICAL PROVISION OF PATIENTS WITH SOCIALLY DANGEROUS PATHOLOGIES
}

\author{
Valeriia Yefremova, Hanna Panfilova, Alla Lebedyn, Gennadii Iurchenko, \\ Oksana Okseniuk, Vitaly Chernukha, Lyubov Tereshchenko, Inna Chebernina
}

\begin{abstract}
The aim: to conduct a comparative analysis of HIV morbidity in Ukraine and in some countries of the European region over the years and to determine the characteristics of the epidemiological situation on this pathology.

Materials and methods. The object of the study was HIV incidence data presented on the website of the WHO European Health Portal (1990-2018) and in the Annual Report of the European Center for Disease Prevention and Control and the WHO Regional Office for Europe on HIV/AIDS Surveillance in Europe (2010-2019). Historical, analyticalcomparative, systemic, graphic, logical, hypothetical-deductive, mathematical-statistical, epidemiological and other research methods were used.

Results. It is established that during 1990-2018 in the group of reference countries only for Ukraine and Belarus there was a significant fluctuation in the incidence rates presented in absolute data. In all countries except Romania, the number of HIV-infected in 2019 was higher than in 1990 (Ukraine, Belarus, Poland) and in 1993 (Germany). Analysis of the dynamics of the absolute number of HIV-infected persons by indicative years (1993, 1999, 2004, 2010, 2016, 2019) allows us to assert the different nature of changes in epidemiological data by group of reference countries. Only in Poland we saw a gradual increase in data for 1993-2019. In all other countries, there was a complex nature of changes in morbidity. According to the analysis of HIV incidence, presented in relative terms, it was found that they ranged in the largest range in Belarus, namely from 11.3 (2010) to 26.1 (2017). Belarus typically had the highest mean chain growth/decline rates of HIV incidence (1.09). In turn, the lowest value of these coefficients was observed in the EU as a whole (0.97). Comparison of average values of HIV incidence per 100 thousand population suggests that in Ukraine this figure was 1.85 times higher than in Belarus, 11.36 times higher than in Poland, 8.65 times higher than in Romania, 10.27 times higher than in Germany and 5.88 times more than in the EU group.

Conclusions. The presence of a complex and tense epidemiological situation with HIV infection in Ukraine in comparison with other countries of the reference group of countries suggests the need to implement comprehensive programs to counter the spread of this socially dangerous infection and introduce models for the rational use of limited health care resources and international funds
\end{abstract}

Keywords: HIV, HIV epidemiology, socially dangerous pathologies, AIDS

\section{How to cite:}

Yefremova, V., Panfilova, H., Lebedyn, A., Iurchenko, G., Okseniuk, O., Chernukha, V., Tereshchenko, L., Chebernina, I. (2022). The results of a comparative analysis of the population of the population of Ukraine and countries of the European region for HIV as a rationale for improving the pharmaceutical provision of patients with socially dangerous pathologies. ScienceRise: Pharmaceutical Science, 1 (35), 4-13. doi: http://doi.org/10.15587/1729-4061.2022.253507

(C) The Author(s) 2022

This is an open access article under the Creative Commons CC BY license hydrate

\section{Introduction}

Among socially dangerous pathologies, the human immunodeficiency virus (HIV) occupies a special place. This is due to a number of factors, including the effectiveness of medical and pharmaceutical care for HIV-infected people and patients with acquired immunodeficiency syndrome (AIDS), their social and regulatory support in society is a priority $[1,2]$. An important place in the fight against the spread of HIV in the world and in different regions is occupied by epidemiological control over the incidence, prevalence, mortality from AIDS [3, 4] and HIV-associated serious pathologies, such as tuberculosis [5] and hepatitis C [6, 7]. Continuous monitoring of these epidemiological indicators is of medical and social importance also because HIV infec- tion against the background of ineffective use of antiretroviral therapy or its absence leads to damage to various organs and systems in a wide range. First of all, cognitive impairments are observed in HIV-infected and AIDS patients [8,9], neurological pathologies of various pathogenesis [10], cardiovascular diseases [11]. The need for lifelong use of antiretroviral drugs [12, 13] under the supervision of a physician, a set of anti-epidemiological measures aimed at preventing the active spread of HIV $[14,15]$, especially among key populations [16] and the implementation of social measures to reduce stigmatization of HIV-infected and AIDS patients in society [17, 18] determines the relevance of the development and effective implementation of areas of rational use of tangible and intangible resources $[19,20]$. The Global Net- 
work for the Collection, Processing, Analysis and Interpretation of Major Epidemiological Indicators of HIV and AIDS was established under the auspices of the WHO in the 1980s and is currently operating effectively $[3,21]$. Every year, the WHO Global Fund to Fight AIDS, Tuberculosis and Malaria allocates a billion for the organization of effective antiretroviral therapy for HIV-infected people around the world, including Ukraine. Despite significant efforts by the international community to address the HIV pandemic and reduce the financial burden of treating AIDS in most low- and middle-income countries, there is a persistent shortage of funds to combat with this dangerous infection [22, 23]. The problem of chronic shortage of funds needed for medical care and pharmaceutical provision to HIVinfected and AIDS patients is especially relevant for the post-Soviet countries [24, 25]. The rapid and uncontrolled spread of HIV in these countries in the 90s of the last century began to be considered by the world community and scientists as an urgent issue in the development of national health systems towards the implementation of humanistic principles of state and society [24, 26]. In the ranking of the WHO European Region, Ukraine has been one of the top three countries in recent decades in terms of HIV intensity $[21,26]$. According to experts, it is impossible to solve this problem by constantly increasing the level of funding for relevant measures for the organization of medical care and pharmaceutical care for HIV-infected people in modern conditions [27, 28]. It is necessary to implement mechanisms for the rational use of limited health resources, primarily aimed at purchasing vital and high-value antiretroviral drugs [29, 30]. An important step in developing effective models of pharmaceutical care for people living with HIV and AIDS in the face of a shortage of funds in the national health care system is the analysis of relevant epidemiological indicators. The research in this direction is especially relevant considering the growing needs of HIVinfected and AIDS patients in medicines (drugs) that have evidence of clinical and economic parameters of their use during antiretroviral therapy [31], including different groups of patients [32, 33]. This statement led to the need for our research.

The purpose of the study is to conduct a comparative analysis of the morbidity of the population of Ukraine and some countries of the European region in retrospect (1990-2019) to develop promising ways to improve the use of limited resources of the national health system and global funds and organizations groups of infectious patients.

\section{Research planning (methodology)}

Research on the dynamics of changes in indicators that characterize the state of the epidemiological situation with HIV in the population of the countries involved the implementation of individual stages of analysis, presented in Table 1. As you could see, the research plan consisted of 8 main stages.

The key stage in our research was "Formation of a statistical research base" (4th stage of analysis). At this stage, it was necessary to resolve two issues related to the formation of a group of reference countries and the definition of epidemiological indicators on which further analysis was envisaged. Given the fact that HIV infection is not only a medical and pharmaceutical problem, but also a socio-economic one for most low- and middleincome countries [36, 37], we used a systematic approach to forming a group of reference countries. Thus, the main criterion used in the formation of the group of reference countries was the similarity with Ukraine in historical, political, socio-economic and other parameters of state development. According to this set of parameters, the most identical to the Ukrainian realities, in our opinion, were Belarus, Poland and Romania. In addition, it was necessary to make comparisons with the EU countries, which were among the first in the world to fight against HIV infection and have made some progress in this direction. These countries, with full responsibility could be attributed to Germany, where the monitoring of epidemiological indicators of HIV infection has been carried out since 1993 [21]. Thus, the group of reference countries included: Ukraine; Belarus; Poland; Romania; Germany.

According to a preliminary analysis of the WHO statistical base, monitoring of HIV infection in various countries around the world is carried out on a wide range of indicators. Therefore, given the format of the research material in the form of an article and the main objectives of our research, it was necessary to choose those indicators that allowed to analyze the state of development and main characteristics of the epidemiological process of HIV infection by group of reference countries. In our opinion, it is the incidence rate that allows us to assess the state of implementation of a set of measures aimed at preventing the spread of this socially dangerous infection in the country. In the future, according to the analysis of morbidity indicators, it is possible to predict the amount of funding, staffing and logistics of health care facilities that provide specialized medical care and pharmaceutical support to HIV-infected and AIDS patients. In contrast to morbidity, prevalence and mortality are integrated indicators that largely reflect the state of the organization of this care for this group of infectious patients. Prevalence and mortality are influenced by a large number of environmental factors in which medical and pharmaceutical care is provided to HIV-infected and AIDS patients. Therefore, we selected the indicators of HIV morbidity for the analysis.

Given the significant time interval for which studies of morbidity (1990-2019) were conducted, it was necessary to determine the indicative years of analysis. At the previous stage, there was a lack of morbidity data (absolute data) during 1990-1992 in Germany. Therefore, to synchronize the analysis and determine the nature of changes in morbidity in the group of reference countries, data from 1993 plus 5 years were selected. That is, in the studies the indicative years were 1993, 1999, 2004, 2010, 2016 and the last year of observation (2019). Data for 2019 for all countries from the reference group were not available on the website of the WHO European Health Portal [34]. Therefore, for the research we used the absolute indicators of HIV incidence in the population, presented in the Annual Report of the European Center for Disease Prevention and Control and the WHO Regional Office for Europe for HIV / AIDS Surveillance in Europe ECDC / WHO HIV / AIDS Surveillance in Europe annual reports (hereinafter - the WHO Annual Report) [21]. 
Plan for applied research

\begin{tabular}{|c|c|}
\hline $\begin{array}{l}\text { The name } \\
\text { of the } \\
\text { stage }\end{array}$ & Analysis of the content and characteristics of the stages of applied research \\
\hline \multicolumn{2}{|r|}{ Substantiation of relevance, socio-economic and medical-pharmaceutical significance of research in this area } \\
\hline $\begin{array}{l}1 \text { stage of } \\
\text { the re- } \\
\text { search }\end{array}$ & $\begin{array}{l}\text { Assessment of the relevance, socio-economic and medical-pharmaceutical significance of epidemiological } \\
\text { research on HIV infection in various countries around the world, mainly in the European region and the } \\
\text { countries formed in the former Soviet Union in the 90s of last century }\end{array}$ \\
\hline \multicolumn{2}{|r|}{ Analysis of the research conducted in this area over the past 5-7 years } \\
\hline $\begin{array}{l}2 \text { stage of } \\
\text { the re- } \\
\text { search }\end{array}$ & $\begin{array}{l}\text { Retrospective years of special literature data, which are presented in the open information space and pre- } \\
\text { sent the results of epidemiological studies on HIV infection in different countries. Thus, we used the data } \\
\text { of the Joint United Nations Program on HIV/AIDS (UNAIDS), the official website of Ukraine on the } \\
\text { WHO website, presenting data on HIV and AIDS (https://www.who.int/hiv/HIVCP_UKR.pdf) and the } \\
\text { WHO European Office (https://www.euro.who.int/en/health-topics/communicable-diseases/hivaids). Par- } \\
\text { ticular attention was paid to the indicators represented by the Center for Public Health of Ukraine (since } \\
\text { its inception in 2015) in the direction of systematic epidemiological surveillance of the population. In the } \\
\text { analysis of data from the special literature on this range of issues, preference was given to data from the } \\
\text { countries of the WHO European Region and the countries formed in the former Soviet Union }\end{array}$ \\
\hline \multicolumn{2}{|r|}{$\begin{array}{c}\text { Formulation of the purpose, development of tasks, definition of objects of research. Outline the main tools used during } \\
\text { the research }\end{array}$} \\
\hline $\begin{array}{l}3 \text { stage of } \\
\text { the re- } \\
\text { search }\end{array}$ & $\begin{array}{l}\text { In accordance with the outlined relevance of the epidemiological analysis in this direction, we have formu- } \\
\text { lated a goal and built a design for future research. According to the analysis of publications on the outlined } \\
\text { topics, we have identified the objects of the research. Using the expert method at this stage, the possibility } \\
\text { of using the data presented in the WHO statistical database was assessed. Research methods were defined } \\
\text { in accordance with the stated purpose, tasks and objects of research }\end{array}$ \\
\hline \multicolumn{2}{|r|}{ Formation of a statistical base of applied research } \\
\hline $\begin{array}{l}4 \text { stage of } \\
\text { the re- } \\
\text { search }\end{array}$ & $\begin{array}{l}\text { At this stage of the research (stage 4) a group of reference countries was formed. It included Ukraine, } \\
\text { Belarus, Poland, Romania, and Germany. In addition, we used summary data from the European Union } \\
\text { (EU) and non-EU countries that are part of the European Economic Area (EEA). According to the WHO, } \\
\text { presented on the European Portal [34] and the Annual Report of the European Center for Disease Preven- } \\
\text { tion and Control and the WHO Regional Office for Europe for HIV / AIDS in Europe [21], key epidemio- } \\
\text { logical indicators were selected. Thus, we analyzed the incidence data, which are presented in absolute } \\
\text { (number of persons) and relative measurements (per } 100 \text { thousand population) for 1990-2019. Statistica } \\
\text { analysis (version 12.0, StatSoft, Tulsa, USA) for further processing, analysis and interpretation }\end{array}$ \\
\hline \multicolumn{2}{|r|}{ Analysis of epidemiological indicators in retrospect of years by group of reference countries } \\
\hline $\begin{array}{l}5 \text { stage of } \\
\text { the re- } \\
\text { search }\end{array}$ & $\begin{array}{l}\text { According to the analysis of statistical data on the morbidity of the population of the reference countries, } \\
\text { the peculiarities of the development of the epidemiological situation with HIV infection of the population } \\
\text { have been determined. To compare the data in retrospect, the indicators of average chronological value, } \\
\text { growth rates }(\%) \text {, growth }(\%) \text {, as well as chain values of growth / decrease ratios were calculated }\left(\mathrm{k}_{\mathrm{kn}+1}\right) \\
\text { [35]. The range of fluctuations in morbidity was carried out using calculations of variation scale }\left(\mathrm{R}=\mathrm{X}_{\max }-\right. \\
\left.\mathrm{X}_{\text {min }}\right) \text { [35]. Two analytical tables were constructed, which present the results of the analysis of absolute } \\
(1990-2019) \text { and relative }(2010-2019) \text { indicators of HIV incidence in the population by group of reference } \\
\text { countries }\end{array}$ \\
\hline \multicolumn{2}{|r|}{ Effective stage of the research } \\
\hline $\begin{array}{l}6 \text { stage of } \\
\text { the re- } \\
\text { search }\end{array}$ & $\begin{array}{l}\text { Systematization, generalization of research results. Construction of graphic material. Description of the } \\
\text { obtained results, determination of the main patterns of development of the epidemiological process of HIV } \\
\text { infection in the group of reference countries }\end{array}$ \\
\hline \multicolumn{2}{|c|}{$\begin{array}{l}\text { Identification of objective limitations in conducting applied research on the outlined topics and their further interpreta- } \\
\text { tion. Outlining areas of promising research on this topic }\end{array}$} \\
\hline $\begin{array}{l}7 \text { stage of } \\
\text { the re- } \\
\text { search }\end{array}$ & $\begin{array}{l}\text { Conducting a critical analysis of the results. Logical modelling of the possibilities of their practical use in } \\
\text { the future. Outlining objective limitations in conducting research, assessing the possibilities of minimizing } \\
\text { their impact when conducting promising research on this topic }\end{array}$ \\
\hline \multicolumn{2}{|r|}{ Generalizing stage } \\
\hline $\begin{array}{l}8 \text { stage of } \\
\text { the re- } \\
\text { search }\end{array}$ & $\begin{array}{l}\text { Based on the results of generalization of the results of the research, the main conclusions of the work are } \\
\text { formulated. Registration of materials of applied researches, writing the article. }\end{array}$ \\
\hline
\end{tabular}

\section{Materials and methods}

The object of the research was the data on HIV incidence, which are presented on the official website of the WHO European Health Portal and in the WHO Annual Report [21, 34]. Data on HIV incidence (Number of new HIV diagnoses. Indicator code: E055303.) in hu- 
mans were analyzed and established during the calendar year. For obvious reasons, Ukrainian data on HIV incidence did not include indicators from the Autonomous Republic of Crimea and the city of Sevastopol since 2014 and from parts of non-government controlled areas since 2015 [34]. The dynamics of changes in the number of new cases of HIV infection in humans and their relative values per 100 thousand population was analyzed. For the convenience of comparative analysis, the incidence of HIV, which is presented in absolute data was tentatively called indicator "A", and in relative - "B".

The analysis used indicators of average chronological values $\left(\overline{\mathrm{y}}=\left(\left(\mathrm{x}_{1}: 2\right)+\mathrm{x}_{2}+\ldots+\mathrm{x}_{\mathrm{n}-1}+\left(\mathrm{x}_{\mathrm{n}}: 2\right)\right)\right.$ : $\left.\mathrm{n}-1\right)$ morbidity of the population of reference countries for HIV infection [35]. Estimation of the range of incidence of morbidity data in the dynamics of years (1990-2019) for the group of reference countries was carried out using the indicator of variation scale $\left(R=X_{\max }-X_{\min }\right)$ [35]. The analysis of the dynamics of changes by years and taking into account the selected indicative years was carried out using growth rates (\%) and growth (\%), as well as chain values of growth / decrease ratios $\left(\mathrm{k}_{\mathrm{kn}+1}\right)$. Statistical data processing was performed using the statistical analysis package Statistica (version 12.0, StatSoft, Tulsa, USA). A p-value $<0.05$ was considered statistically significant.

In our research we used two groups of research methods, namely general theoretical (historical, graphic, generalization, hypothetical-deductive, grouping, etc.) and applied (epidemiological analysis, organizationaleconomic, mathematical-statistical, etc.).

\section{Research results}

The results of the analysis of the dynamics of changes in indicators A and B are presented in Tables 1 and 2. From 1990 to 2019, indicator A in Ukraine increased 962.2 times, from 17 to 16,357 people (variation range is 16,340 units), in Belarus 152.6 times from 14 to 2,137 people $(\mathrm{R}=2123)$, in Poland 1.81 times from 813 to 1468 people ( $\mathrm{R}=655$ ). In Germany, from 1993 to 2019, the indicator A increased only 1.31 times from 2360 to 3093 people ( $R=733$ ), and in Romania we observed the opposite trend, namely a decrease in the corresponding figures from 1860 to 690 people. Thus, the rate (\%) of decline in indicator A in Romania in 2019 compared to 1990 was $37.1 \%$.

Table 1

The results of the analysis of indicator A (morbidity in absolute data, persons) of the population in the reference countries for HIV

\begin{tabular}{|c|c|c|c|c|c|c|c|c|c|c|}
\hline \multirow{2}{*}{ Years } & \multicolumn{2}{|c|}{ Ukraine } & \multicolumn{2}{|c|}{ Belarus } & \multicolumn{2}{|c|}{ Poland } & \multicolumn{2}{|c|}{ Romania } & \multicolumn{2}{|c|}{ Germany } \\
\hline & Indicator & $\mathrm{k}$ & Indicator & $\mathrm{k}$ & Indicator & $\mathrm{k}$ & Indicator & $\mathrm{k}$ & Indicator & $\mathrm{k}$ \\
\hline 1990 & 17 & - & 14 & - & 813 & - & 1860 & - & - & - \\
\hline 1991 & 19 & 1.12 & 12 & 0.85 & 558 & 0.69 & 796 & 0.43 & - & - \\
\hline 1992 & 28 & 1.47 & 21 & 1.75 & 482 & 0.86 & 738 & 0.93 & - & - \\
\hline 1993* & 39 & 1.39 & 10 & 0.48 & 389 & 0.81 & 728 & 0.99 & 2360 & - \\
\hline 1994 & 31 & 0.80 & 5 & 0.50 & 430 & 1.11 & 843 & 1.16 & 2265 & 0.96 \\
\hline 1995 & 1481 & 47.77 & 8 & 1.6 & 544 & 1.27 & 1035 & 1.23 & 2229 & 0.98 \\
\hline 1996 & 5308 & 3.58 & 1021 & 127.63 & 550 & 1.01 & 1036 & 1.01 & 1871 & 0.84 \\
\hline 1997 & 8717 & 1.64 & 653 & 0.64 & 581 & 1.06 & 1036 & 1.00 & 2070 & 1.11 \\
\hline 1998 & 8197 & 0.94 & 554 & 0.85 & 643 & 1.11 & 935 & 0.90 & 1924 & 0.93 \\
\hline 1999* & 5300 & 0.65 & 411 & 0.74 & 537 & 0.84 & 885 & 0.95 & 1746 & 0.91 \\
\hline 2000 & 5485 & 1.03 & 527 & 1.28 & 630 & 1.17 & 835 & 0.94 & 1688 & 0.97 \\
\hline 2001 & 6086 & 1.11 & 578 & 1.10 & 577 & 0.92 & 830 & 0.99 & 2882 & 1.71 \\
\hline 2002 & 7385 & 1.21 & 915 & 1.58 & 571 & 0.99 & 748 & 0.90 & 1714 & 0.60 \\
\hline 2003 & 6478 & 0.88 & 713 & 0.78 & 701 & 1.23 & 681 & 0.91 & 1977 & 1.15 \\
\hline 2004* & 10404 & 1.61 & 778 & 1.09 & 646 & 0.92 & 624 & 0.92 & 2225 & 1.13 \\
\hline 2005 & 11464 & 1.10 & 751 & 0.97 & 680 & 1.05 & 600 & 0.96 & 2490 & 1.11 \\
\hline 2006 & 13456 & 1.17 & 733 & 0.98 & 703 & 1.03 & 508 & 0.85 & 2638 & 1.06 \\
\hline 2007 & 13469 & 1.01 & 990 & 1.35 & 724 & 1.03 & 490 & 0.97 & 2765 & 1.05 \\
\hline 2008 & 15444 & 1.15 & 881 & 0.89 & 809 & 1.12 & 575 & 1.17 & 2824 & 1.02 \\
\hline 2009 & 16268 & 1.05 & 1072 & 1.22 & 962 & 1.19 & 576 & 1.01 & 2911 & 1.03 \\
\hline 2010* & 16617 & 1.02 & 1069 & 0.99 & 955 & 0.99 & 586 & 1.02 & 2803 & 0.96 \\
\hline 2011 & 17305 & 1.04 & 1196 & 1.12 & 1113 & 1.17 & 831 & 1.42 & 2761 & 0.99 \\
\hline 2012 & 16850 & 0.97 & 1223 & 1.02 & 1102 & 0.99 & 927 & 1.12 & 3020 & 1.09 \\
\hline 2013 & 17844 & 1.06 & 1533 & 1.25 & 1100 & 0.99 & 1000 & 1.08 & 3232 & 1.07 \\
\hline 2014 & 15796 & 0.89 & 1811 & 1.18 & 1132 & 1.03 & 883 & 0.88 & 3521 & 1.09 \\
\hline 2015 & 13000 & 0.82 & 2305 & 1.27 & 1278 & 1.13 & 860 & 0.97 & 3635 & 1.03 \\
\hline 2016* & 14250 & 1.10 & 2391 & 1.04 & 1315 & 1.03 & 750 & 0.87 & 3373 & 0.93 \\
\hline 2017 & 15640 & 1.10 & 2468 & 1.03 & 1419 & 1.08 & 762 & 1.02 & 3144 & 0.93 \\
\hline 2018 & 15749 & 1.01 & 2368 & 0.96 & 1165 & 0.82 & 669 & 0.88 & 2818 & 0.90 \\
\hline 2019* & 16357 & 1.04 & 2137 & 0.90 & 1468 & 1.26 & 690 & 1.03 & 3093 & 1.10 \\
\hline Average value & 9816.33 & - & 971.60 & - & 796.86 & - & 819.23 & - & 2591.82 & - \\
\hline
\end{tabular}


Analyzing the results of Table 1 , it is necessary to pay attention to the significant growth of indicator A in Ukraine in 1995 and in Belarus in 1996. Thus, in Ukraine indicator A increased from 31 to 1481 persons (increase of 47.77 times), and in Belarus - from 8 to 1021 people (an increase of 127.63 times). In other countries of the reference group, such a rapid increase in the number of HIV-infected people was not observed during 19902019. It is established that except for data for 1995 (Ukraine) and 1996 (Belarus), the maximum values of growth rates $(\%)$ of chain indicators $\mathrm{A}$ in Ukraine were observed in 1996 (258.0\%), in Belarus in 1995 (60.0 \%), in Poland in 1995 (27.0 \%), in Romania in 2011 (42.0
$\%$ ), and in Germany - in 2003 (13.0\%). As we could see, it was in Ukraine that we observed the highest values of growth rates (\%) for the group of reference countries. We found that in Ukraine the indicator A decreased compared to the previous period (chain values) by 7 years, in Belarus - by 12 years, in Poland - by 11 years, in Romania - by 17 years, and in Germany (WHO indicators have been monitored since 1993) - for 12 years.

Given the significant time interval for which the data of indicator A (1990-2010) were analyzed, diagrams of changes in indicator A by indicative years were constructed. The results of the analysis are shown in Fig. 1-3.

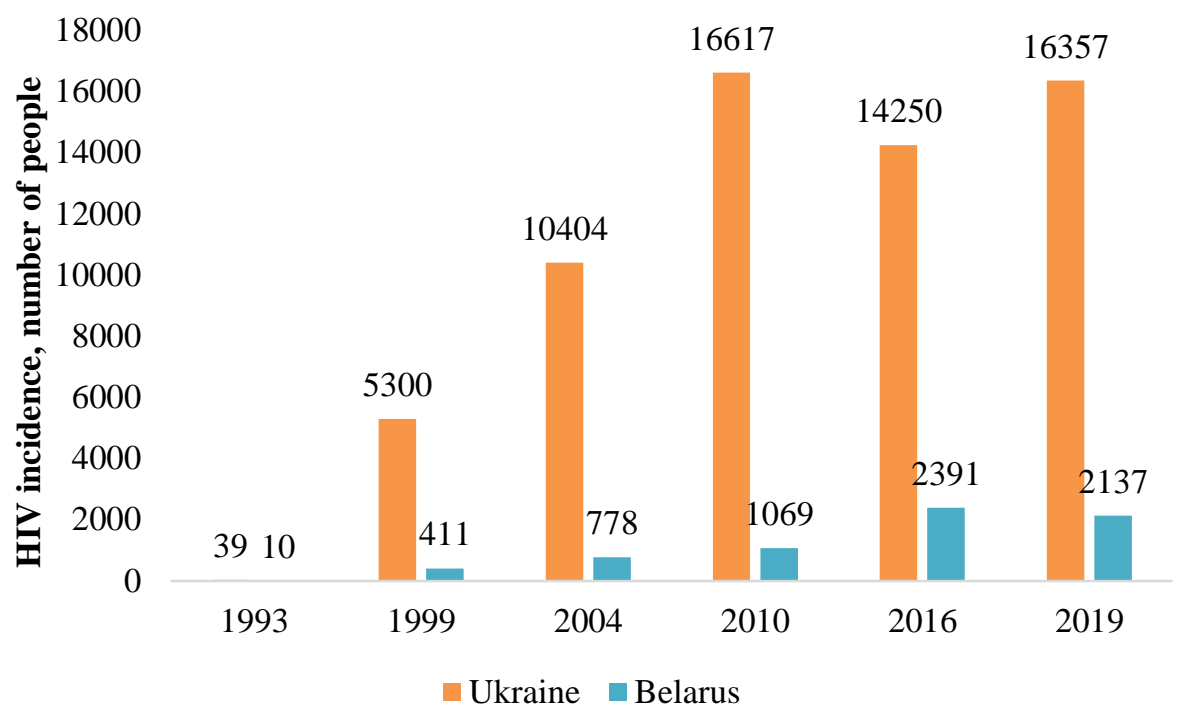

Fig. 1. Analysis of the dynamics of changes in indicator A for indicative years in Ukraine and Belarus

It should be noted that all countries, except Poland, had a complex nature of changes in indicators A. Thus, in Poland, according to the indicative years, there was a systematic increase in the number of infected people. Their number in 2019, compared to 1993, increased 3.77 times. The zigzag nature of changes in epidemiological indicators was observed in Ukraine, Romania and Germany. In Ukraine during 1993-2010 there was an intensive growth of data, and according to 2016 data the number of infected decreased to 14,250 people, which was $14.24 \%$ less than according to 2010 data (16,617 people). Subsequently, we observed an increase in epidemiological indicators to 16,357 people, which was $14.8 \%$ higher than in 2016. In Belarus, an increase in indicators A was observed until 2016 (2391 people), and a decrease in data by $10.62 \%$ (2137 people) was typical for 2019. That is, in comparison with Ukraine in Belarus there was a slower change in A during the period under study.

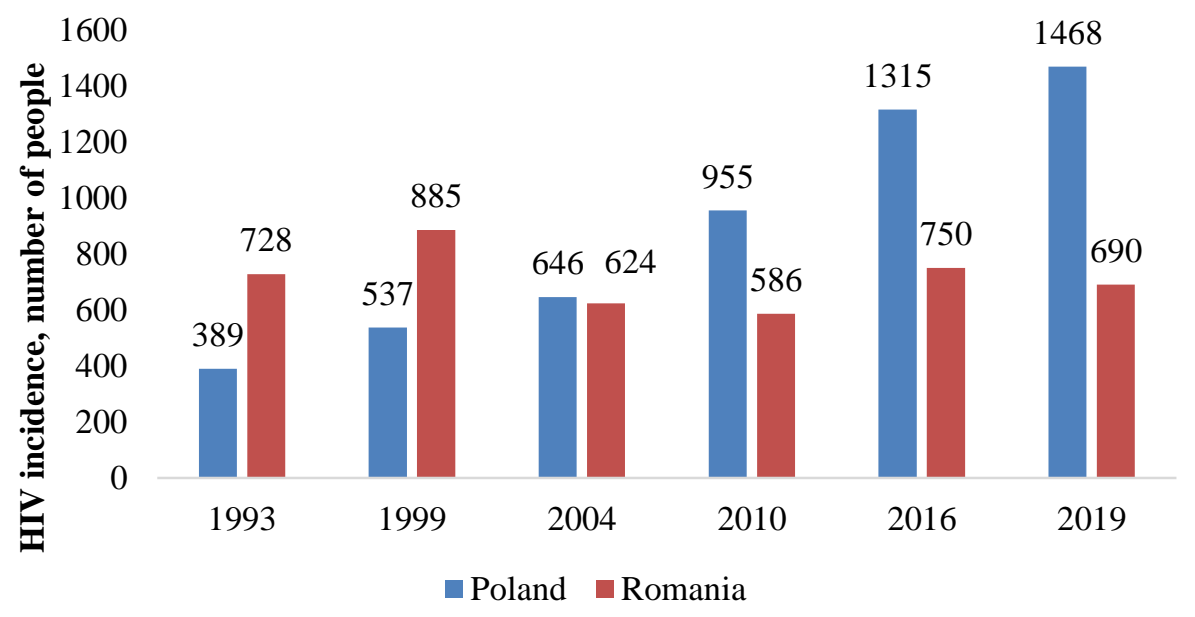

Fig. 2. Results of the analysis of the dynamics of changes in indicator A by indicative years in Poland and Romania 
In Romania, there was an increase in $\mathrm{A}$ in a much shorter time range than in the group of reference countries. Thus, there was an increase in indicators A in 1999 (885 people) by $21.56 \%$ compared to 1993 (728 people), and then there was a gradual increase in data to 750 people in 2016.

As in Germany and Belarus, epidemiological indicators in Romania according to 2019 also decreased (-8.0 \%) compared to 2016. Germany was the only group in the reference countries which was characterized by a decrease in epidemiological indicators in 1999. That is, this country in seven years (from 19931999) has made some progress in combating the spread of HIV among the population. Thus, according to 1999 data, the number of new cases of HIV infection (1746 people) decreased compared to 1993 (2360 people) by $26.02 \%$. Subsequently, there was a systematic increase in data to maximum values in 2016 (3373 people). In 2019, we managed to reduce the epidemiological burden of HIV infection in society and the number of new cases was 3,093 people, which is $8.3 \%$ lower than in 2016. Thus, it could be argued that the countries of the reference group had different in nature changes in the dynamics of the years.

The next direction of our research was a comparative analysis of these indicators B (Table 2).

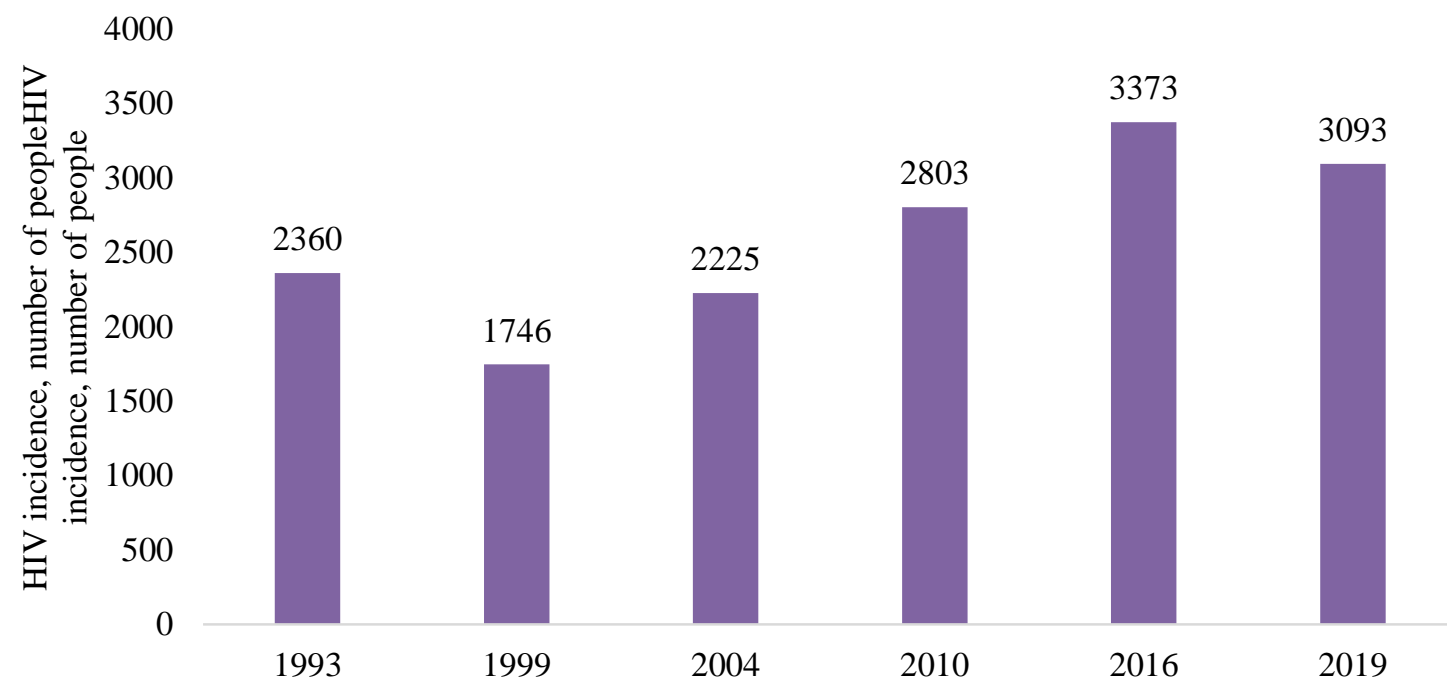

Fig. 3. Study of the dynamics of changes in indicator A for indicative years in Germany

Table 2

Analysis of these indicators B (morbidity and HIV infection per 100 thousand people) in the reference countries, in general in the EU, EEA

\begin{tabular}{|c|c|c|c|c|c|c|c|c|c|c|c|c|c|c|}
\hline \multirow[b]{2}{*}{ Years } & \multicolumn{2}{|c|}{ Ukraine } & \multicolumn{2}{|c|}{ Belarus } & \multicolumn{2}{|c|}{ Poland } & \multicolumn{2}{|c|}{ Romania } & \multicolumn{2}{|c|}{ Germany } & \multicolumn{2}{|c|}{ EU countries } & \multicolumn{2}{|c|}{ EEA countries } \\
\hline & $\begin{array}{l}\text { Mor. } \\
(100 \\
\text { thous.) }\end{array}$ & $\mathrm{k}$ & $\begin{array}{l}\text { Mor. } \\
(100 \\
\text { thous.) }\end{array}$ & $\mathrm{k}$ & $\begin{array}{l}\text { Mor. } \\
(100 \\
\text { thous.) }\end{array}$ & $\mathrm{k}$ & $\begin{array}{l}\text { Mor. } \\
\text { (100 } \\
\text { thous.) }\end{array}$ & $\mathrm{k}$ & $\begin{array}{l}\text { Mor. } \\
(100 \\
\text { thous.) }\end{array}$ & $\mathrm{k}$ & $\begin{array}{l}\text { Mor. } \\
\text { (100 } \\
\text { thous.) }\end{array}$ & $\mathrm{k}$ & $\begin{array}{l}\text { Mor. } \\
\text { (100 } \\
\text { thous.) }\end{array}$ & $\mathrm{k}$ \\
\hline 2010 & 36.3 & - & 11.3 & - & 2.5 & - & 2.9 & - & 3.4 & - & 6.6 & - & 23.8 & - \\
\hline 2011 & 37.9 & 1.02 & 12.7 & 1.12 & 2.9 & 1.16 & 4.1 & 1.41 & 3.2 & 0.94 & 6.6 & 1.00 & 26.2 & 1.10 \\
\hline 2012 & 37.1 & 0.98 & 13.0 & 1.02 & 2.9 & 1.00 & 4.7 & 1.15 & 2.9 & 0.91 & 6.8 & 1.03 & 28.4 & 1.08 \\
\hline 2013 & 39.4 & 1.06 & 16.3 & 1.25 & 2.9 & 1.00 & 5.1 & 1.09 & 2.9 & 1.00 & 6.6 & 0.97 & 30.3 & 1.07 \\
\hline 2014 & 35.0 & 0.88 & 19.2 & 1.18 & 3.0 & 1.03 & 5.4 & 1.06 & 3.3 & 1.14 & 6.5 & 0.98 & 33.0 & 1.09 \\
\hline 2015 & 30.4 & 0.87 & 24.4 & 1.27 & 3.4 & 1.13 & 4.4 & 0.82 & 4.5 & 1.36 & 6.2 & 0.95 & 34.7 & 1.05 \\
\hline 2016 & 33.4 & 1.10 & 25.3 & 1.04 & 3.5 & 1.03 & 3.9 & 0.89 & 4.1 & 0.91 & 6.2 & 1.00 & 31.3 & 0.90 \\
\hline 2017 & 36.8 & 1.10 & 26.1 & 1.03 & 3.7 & 1.06 & 4.1 & 1.05 & 3.8 & 0.93 & 5.9 & 0.95 & 31.4 & 1.01 \\
\hline 2018 & 37.2 & 1.01 & 25.2 & 0.97 & 3.2 & 0.87 & 3.7 & 0.90 & 3.5 & 0.92 & 5.3 & 0.90 & 31.6 & 1.01 \\
\hline 2019 & 39.0 & 1.05 & 22.6 & 0.90 & 3.9 & 1.22 & 3.6 & 0.97 & 3.7 & 1.06 & 4.9 & 0.93 & 30.1 & 0.95 \\
\hline $\begin{array}{c}\text { Average } \\
\text { value }\end{array}$ & 36.25 & 1.01 & 19.61 & 1.09 & 3.19 & 1.06 & 4.19 & 1.04 & 3.53 & 1.02 & 6.16 & 0.97 & 30.08 & 1.03 \\
\hline
\end{tabular}

As can be seen from Table 2, in the group of reference countries there was a different range of fluctuations of this epidemiological indicator. Thus, in Ukraine it ranged from 30.4 (2005) to 39.00 (2019), in Belarus from 11.3 (2010) to 26.1 (2017), in Poland - from 2.5 (2010) to 3.9 (2019), and in Romania - from 2.9 (2010) to 5.4 (2014). In Germany, B ranged from 2.9 (2012 and 2013) to 4.5 (2015). In the EU group as a whole, B ranged from 4.9 (2019) to 6.8 (2012), and for the EEA from 23.8 (2010) to 34.7 (2015)). As you could see, the largest range of fluctuations in B was observed in Belarus. We also calculated the values of the average chain growth / decline ratios for the group of reference countries. Thus, in Ukraine this indicator was equal to 1.01, in Belarus -1.09 , in Poland -1.06 , in Romania 1.04, in Germany - 1.02. In general, for the group of EU countries, this indicator, which characterizes the dynamics of changes in epidemiological indicators was 0.97 , and in the group of EEA countries - 1.03. Thus, it could be argued that European countries during 2010-2019 man- 
aged to effectively cope with the trend of increasing HIV incidence, which could not be said about the EEA countries (average growth rate of $3.0 \%$ ).

Given the relative nature of indicators B, we subsequently calculated the average chronological data for 2010-2019 for the group of reference countries. The results of comparative analysis are shown in Fig. 4. It is necessary to note the striking fact of the separation of Ukrainian indicators from all other countries on indicator
B. Thus, in Ukraine the average value of indicator B was 1.85 times more than in Belarus, 11.36 times more than in Poland, 8, 65 times more than in Romania and 10.27 times more than in Germany. It is logical that the Ukrainian indicator B exceeded similar data, which were observed in the EU as a whole by 5.88 times. In addition, the incidence of HIV (relative per 100,000 population) in Ukraine was 1.21 times higher than in the EEA countries as a whole.

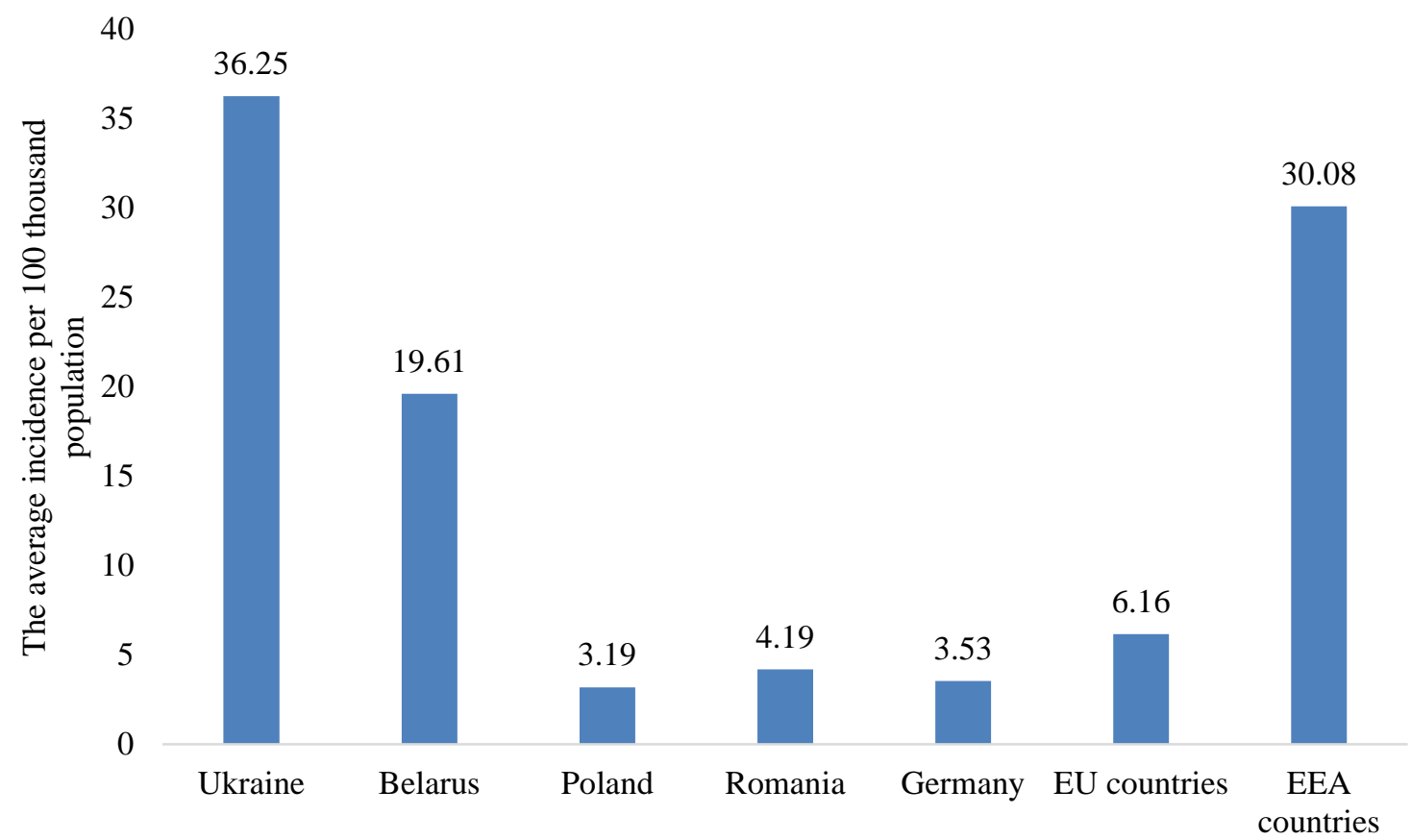

Fig. 4. Results of the comparative analysis of average indicators B by group of reference countries during 2010-2019

Analyzing the dynamics of chain values of rates (\%) of indicators B in the group of reference countries, it should be noted that in Ukraine the indicators decreased compared to the previous three years $(2012,2014,2015)$, in Belarus - only for two years $(2018,2019)$, in Poland only for one year (2018), in Romania - for four years $(2015,2016,2018,2019)$, and in Germany - for five years $(2011,2012,2016,2017,2018)$. Positive is the fact that in the EU the B indicator in the dynamics of years decreased compared to previous years by seven years (2013, 2014, 2015, 2016-2019). In the EEA countries, a similar downward trend in B indicators was observed only for two years (2016 and 2019).

\section{Discussion}

Systematizing the results of the research, we could identify the following characteristics of the epidemiological process in the group of reference countries during 1990-2019. Thus, only Ukraine (from 31 to 1481 people) and Belarus (from 8 to 1021 people) was characterized by a significant increase in indicators $\mathrm{A}$ 1995 and 1996, respectively. In all other countries, we observed fluctuations in the much smaller range of values. This fact could not be assessed unequivocally. In our opinion, it does not indicate a catastrophic increase in the number of infections per calendar year but is cumulative and is the result of a significant increase in the level of their detection. As you know, in the 1990s, Ukraine and
Belarus, which gained independence after the collapse of the Soviet Union, were in a state of crisis in all areas of state and society. According to the WHO, Ukraine has been monitoring HIV-infected people since 1988, and Belarus only since 1991. Later, in Ukraine and Belarus, with the active support of the WHO and the state, the situation with HIV spread has stabilized. Thus, in Ukraine in 1998 the indicator decreased by $6.0 \%$ compared to the previous period, and in 1999 by $35.0 \%$. A similar trend was characteristic of the Belarusian data, so that indicator A in 1997 decreased by $36.0 \%$, and in the following 1998 by $26.0 \%$. In the following years, in Ukraine and Belarus, indicator A fluctuated in a much smaller range of values. The only exception is the data for Ukraine in 2004, when the number of HIV-infected people increased by $61.0 \%$ compared to 2003.

In all countries of the reference group, except Romania, the number of HIV-infected in 2019 was higher than in 1990 (Ukraine, Belarus, Poland) and in 1993 (Germany). It should also be noted that the lowest rates (\%) of growth, compared to other countries, A indicators had in Germany. Analysis of the dynamics of indicators $A$ by indicative years allows us to argue about the different nature of changes in epidemiological data for the group of reference countries. Thus, only in Poland we observed a gradual increase in data during 1993-2019. The presence of different nature of changes in indicators A leads to separate studies for each country. 
According to the analysis of the dynamics of indicators B, it could be stated that among the group of reference countries it fluctuated in a different range of values during 2010-2019. In the largest range of values, indicator B fluctuated in Belarus. The second position in the range of fluctuations was represented by Ukrainian indicators, the third position - data from Romania, the fourth data from Poland, and closes this conditional rating of the relevant data presented in Germany.

Of particular concern are the results of a comparative analysis of the average values of indicator B in Ukraine with similar data for the group of reference countries. As we could see, despite the significant successes of Ukrainian health care in combating the spread of infectious diseases, including HIV and tuberculosis [38], the issue of raising the level of epidemiological protection against the population under adverse socioeconomic situation in the country remains relevant. It should also be noted that in Ukraine, indicator B since 2016 had a negative nature of data growth in contrast to Belarus and Germany. Against this background, the fact that since 2016 the growth rate $(\%)$ of indicator B in Ukraine has been gradually slowing down looks positive. For example, in 2016-2017 we observed an annual increase in indicators B at the level of $10.0 \%$, and according to 2018 there was an increase in data by only $1.0 \%$.

According to the group of reference countries, the highest values of the average growth/decrease rate of $\mathrm{B}$ were observed in Belarus (1.09), and the lowest - according to EU countries (0.97). In general, it should be noted that the fact that in the EU countries during 2017-2019 there was a systematic decrease in the data of indicator B (from 5.9 to 4.9 people per 100 thousand population). A similar situation took place during 2018-2019, according to indicator B in Belarus, Romania and Germany.

Study limitations. The main limitations in conducting research and further interpretation of their results include the lack of updated data on indicators A and B, which are presented in 2019. Thus, on the official website of the WHO European Council, indicators for 2019 were missing in all countries, despite the fact that the last update of data took place on 06.09.2020 [34]. Therefore, indicators A and B for 2019 were selected based on operational data presented in the WHO Annual Report for 2020 [21]. The operational data for 2019 on indicators A and B will be further adjusted based on the results of cooperation with the relevant bodies of national health systems. In addition, it raises questions about the formation of a database of epidemiological indicators in Romania. Thus, the website of the WHO European Bureau states that the number of new HIV infections (indicator code: E055303.T) in Romania could be adjusted to the number of AIDS patients in whom the infection was diagnosed for the first time in the expanded clinical picture [34].

In general, it is also necessary to determine that the presented results could not be used for a comprehensive assessment of the state of development of the epidemiological situation with HIV infection in the reference countries. In order to conduct more thorough research in this area, it is also necessary to conduct a structural analysis of the incidence, prevalence and mortality of HIV-infected people over the years, but such research is beyond the scope of our work. Our results allow us to follow the development of the epidemiological process in one of its areas, first of all, we could compare the effectiveness of anti-epidemiological measures and the level of timely detection and early diagnosis of this infection in humans. The outlined limitations of the conducted research could certainly further affect the effectiveness of their interpretation. It should be noted that their results could predict the financial support of the process of providing pathogenetic therapy to $\mathrm{HIV}$-infected people using antiretroviral drugs 1 series of chemotherapy, which is carried out in the early stages of the pathological process. It is known that effective antiretroviral therapy in the early stages of the pathological process could significantly reduce the cost of treatment of HIV-infected and AIDS patients in the future [39, 40].

Prospects for further research. One of the promising areas of research on this topic is to analyze the impact of various factors on the dynamics of changes in indicators $\mathrm{A}$ and $\mathrm{B}$, as well as the prevalence and mortality of AIDS patients. First of all, it is interesting to conduct this analysis taking into account the level of coverage of HIV-infected people with antiretroviral therapy in Ukraine. As you know, this indicator is considered by the WHO as an important indicative parameter by which to assess the effectiveness of the fight against HIV and AIDS at the macroeconomic level [39, 41]. In turn, addressing the issue of improving the effectiveness of treatment and early detection of HIV infections is an important task in addressing the objectives of the WHO's "Sustainable Development Goals" and the formation of stable socioeconomic dominants in society as a whole [21, 42].

Given the medical and social importance of reducing the incidence of children in HIV, which is constantly emphasized by the WHO, one of the promising areas of our research will be to analyze the dynamics of changes in morbidity, prevalence and mortality of AIDS. The need for further implementation of the regional approach in the process of rational allocation of state allocations and resources of international funds and organizations determines the prospects of analyzing the dynamics of changes in epidemiological indicators of HIV and AIDS in terms of different administrative units of Ukraine.

\section{Conclusions}

Summing up the results of the research, it can be argued that increasing the effectiveness of early detection of HIV among the population of Ukraine should be considered as an issue that needs to be addressed comprehensively. In our opinion, a planned increase in funding for health care and pharmaceutical care for HIV-infected people without considering the impact of socio-economic factors on society is short-sighted. It is necessary to form sustainable models of safe behaviour in youth, reduce the level of stigmatization of HIV-infected people and implement effective prevention activities among target groups with a high risk of socially dangerous infectious diseases.

\section{Conflict of interests}

The authors declare that they have no conflicts of interest.

Financing

The study was performed without financial support. 


\section{Acknowledgment}

The conducted research is a component of the process of performance of scientific works which are carried out in the direction of development and introduction of directions of improvement of pharmaceutical maintenance of various groups of patients. Effective conduct of these studies would be impossible without the theoretical and applied achievements of the organizational and economic school, which operates at the National University of Pharmacy.

\section{References}

1. Corneli, A., Meagher, K., Henderson, G., Peay, H., Rennie, S. (2018). How Biomedical HIV Prevention Trials Incorporate Behavioral and Social Sciences Research: A Typology of Approaches. AIDS and Behavior, 23 (8), 2146-2154. doi: http://doi.org/10.1007/ s10461-018-2358-0

2. Ferris France, N., Macdonald, S. H.-F., Conroy, R. R., Chiroro, P., Ni Cheallaigh, D., Nyamucheta, M. et. al. (2019). "We are the change" - An innovative community-based response to address self-stigma: A pilot study focusing on people living with HIV in Zimbabwe. PLOS ONE, 14 (2), e0210152. doi: http://doi.org/10.1371/journal.pone.0210152

3. Spach, D. H. (2021). Epidemiology of HIV. National HIV Curriculum. Available at: https://www.hiv.uw.edu/go/ screening-diagnosis/epidemiology/core-concept/all

4. Gokengin, D., Oprea, C., Begovac, J., Horban, A., Zeka, A. N., Sedlacek, D. et. al. (2018). HIV care in Central and Eastern Europe: How close are we to the target? International Journal of Infectious Diseases, 70, 121-130. doi: http://doi.org/10.1016/j.ijid.2018.03.007

5. Murray, C. J. L., Ortblad, K. F., Guinovart, C., Lim, S. S., Wolock, T. M., Roberts, D. A. et. al. (2014). Global, regional, and national incidence and mortality for HIV, tuberculosis, and malaria during 1990-2013: a systematic analysis for the Global Burden of Disease Study 2013. The Lancet, 384 (9947), 1005-1070. doi: http://doi.org/10.1016/s0140-6736(14)60844-8

6. Peters, L., Klein, M. B. (2015). Epidemiology of hepatitis C virus in HIV-infected patients. Current Opinion in HIV and AIDS, 10 (5), 297-302. doi: http://doi.org/10.1097/coh.0000000000000183

7. Klein, M. B., Rockstroh, J. K., Wittkop, L. (2016). Effect of coinfection with hepatitis C virus on survival of individuals with HIV-1 infection. Current Opinion in HIV and AIDS, 11 (5), 521-526. doi: http://doi.org/10.1097/coh.0000000000000292

8. Tedaldi, E. M., Minniti, N. L., Fischer, T. (2015). HIV-Associated Neurocognitive Disorders: The Relationship of HIV Infection with Physical and Social Comorbidities. BioMed Research International, 2015, 1-13. doi: http://doi.org/10.1155/2015/641913

9. Cohen, R. A., Seider, T. R., Navia, B. (2015). HIV effects on age-associated neurocognitive dysfunction: premature cognitive aging or neurodegenerative disease? Alzheimer's Research \& Therapy, 7 (1). doi: http://doi.org/10.1186/s13195-015-0123-4

10. Hoffmann, C., Welz, T., Sabranski, M., Kolb, M., Wolf, E., Stellbrink, H.-J., Wyen, C. (2016). Higher rates of neuropsychiatric adverse events leading to dolutegravir discontinuation in women and older patients. HIV Medicine, 18 (1), 56-63. doi: http://doi.org/10.1111/hiv.12468

11. Alonso, A., Barnes, A. E., Guest, J. L., Shah, A., Shao, I. Y., Marconi, V. (2019). HIV Infection and Incidence of Cardiovascular Diseases: An Analysis of a Large Healthcare Database. Journal of the American Heart Association, 8 (14). doi: http://doi.org/10.1161/ jaha.119.012241

12. Ingle, S. M., May, M. T., Gill, M. J., Mugavero, M. J., Lewden, C. et. al. (2014). Impact of Risk Factors for Specific Causes of Death in the First and Subsequent Years of Antiretroviral Therapy Among HIV-Infected Patients. Clinical Infectious Diseases, 59 (2), 287-297. doi: http://doi.org/10.1093/cid/ciu261

13. Kay, E. S., Batey, D. S., Mugavero, M. J. (2016). The HIV treatment cascade and care continuum: updates, goals, and recommendations for the future. AIDS Research and Therapy, 13 (1). doi: http://doi.org/10.1186/s12981-016-0120-0

14. Luz, P. M., Veloso, V. G., Grinsztejn, B. (2019). The HIV epidemic in Latin America: accomplishments and challenges on treatment and prevention. Current Opinion in HIV and AIDS, 14 (5), 366-373. doi: http://doi.org/10.1097/coh.0000000000000564

15. Chammartin, F., Zürcher, K., Keiser, O., Weigel, R., Chu, K., Kiragga, A. N. et. al. (2018). Outcomes of Patients Lost to Follow-up in African Antiretroviral Therapy Programs: Individual Patient Data Meta-analysis. Clinical Infectious Diseases, 67 (11), 1643-1652. doi: http://doi.org/10.1093/cid/ciy347

16. Hernandez, I., Reina-Ortiz, M., Johnson, A., Rosas, C., Sharma, V., Teran, S. et. al. (2016). Risk Factors Associated With HIV Among Men Who Have Sex With Men (MSM) in Ecuador. American Journal of Men's Health, 11 (5), 1331-1341. doi: http://doi.org/10.1177/1557988316646757

17. Pantelic, M., Steinert, J. I., Park, J., Mellors, S., Murau, F. (2019). "Management of a spoiled identity": systematic review of interventions to address self-stigma among people living with and affected by HIV. BMJ Global Health, 4 (2). doi: http://doi.org/10.1136/bmjgh-2018-001285

18. Gaist, P., Stirratt, M. J. (2017). The Roles of Behavioral and Social Science Research in the Fight Against HIV/AIDS: A Functional Framework. JAIDS Journal of Acquired Immune Deficiency Syndromes, 75 (4), 371-381. doi: http://doi.org/10.1097/ qai.0000000000001399

19. Frank, T. D., Carter, A., Jahagirdar, D., Biehl, M. H., Douwes-Schultz, D., Larson, S. L. et. al. (2019). Global, regional, and national incidence, prevalence, and mortality of HIV, 1980-2017, and forecasts to 2030, for 195 countries and territories: a systematic analysis for the Global Burden of Diseases, Injuries, and Risk Factors Study 2017. The Lancet HIV, 6 (12), e831-e859. doi: http://doi.org/10.1016/s2352-3018(19)30196-1

20. Saag, M. S., Benson, C. A., Gandhi, R. T., Hoy, J. F., Landovitz, R. J., Mugavero, M. J. et. al. (2018). Antiretroviral Drugs for Treatment and Prevention of HIV Infection in Adults. JAMA, 320 (4), 379-396. doi: http://doi.org/10.1001/jama.2018.8431

21. HIV/AIDS surveillance in Europe 2020 (2019). WHO, 126. Available at: https://www.ecdc.europa.eu/sites/default/files/ documents/hiv-surveillance-report-2020.pdf

22. Ahmed, S., Autrey, J., Katz, I. T., Fox, M. P., Rosen, S., Onoya, D. et. al. (2018). Why do people living with HIV not initiate treatment? A systematic review of qualitative evidence from low- and middle-income countries. Social Science \& Medicine, 213, 72-84. doi: http://doi.org/10.1016/j.socscimed.2018.05.048

23. Pellowski, J. A., Kalichman, S. C., Matthews, K. A., Adler, N. (2013). A pandemic of the poor: Social disadvantage and the U.S. HIV epidemic. American Psychologist, 68 (4), 197-209. doi: http://doi.org/10.1037/a0032694

24. Saadat, V. M. (2016). HIV Risks, Testing, and Treatment in the Former Soviet Union: Challenges and Future Directions in Research and Methodology. Central Asian Journal of Global Health, 4 (2). doi: http://doi.org/10.5195/cajgh.2015.225

25. Amangaldiyeva, A., Davlidova, S., Baiserkin, B., Dzissyuk, N., DeHovitz, J., Ali, S. (2019). Implementation of antiretroviral therapy (ART) in former Soviet Union countries. AIDS Research and Therapy, 16 (1). doi: http://doi.org/10.1186/s12981-019-0251-1

26. Rechel, B. (2010). HIV/AIDS in the Countries of the Former Soviet Union: Societal and Attitudinal Challenges. Central European Journal of Public Health, 18 (2), 110-115. doi: http://doi.org/10.21101/cejph.a3583

27. Piot, P., Caldwell, A., Lamptey, P., Nyrirenda, M., Mehra, S., Cahill, K., Aerts, A. (2016). Addressing the growing burden of non-communicable disease by leveraging lessons from infectious disease management. Journal of Global Health, 6 (1). doi: http://doi.org/10.7189/jogh.06.010304 
28. Frijters, E. M., Hermans, L. E., Wensing, A. M. J., Devillé, W. L. J. M., Tempelman, H. A., De Wit, J. B. F. (2020). Risk factors for loss to follow-up from antiretroviral therapy programmes in low-income and middle-income countries. AIDS, 34 (9), 1261-1288. doi: http://doi.org/10.1097/qad.0000000000002523

29. Dybul, M., Attoye, T., Baptiste, S., Cherutich, P., Dabis, F., Deeks, S. G. et. al. (2021). The case for an HIV cure and how to get there. The Lancet HIV, 8 (1), e51-e58. doi: http://doi.org/10.1016/s2352-3018(20)30232-0

30. Miners, A., Phillips, A., Kreif, N., Rodger, A., Speakman, A., Fisher, M. et. al. (2014). Health-related quality-of-life of people with HIV in the era of combination antiretroviral treatment: a cross-sectional comparison with the general population. The Lancet HIV, 1 (1), e32-e40. doi: http://doi.org/10.1016/s2352-3018(14)70018-9

31. Jacobson, J. M., Flexner, C. W. (2017). Universal antiretroviral regimens: thinking beyond one-pill-once-a-day. Current Opinion in HIV and AIDS, 12 (4), 343-350. doi: http://doi.org/10.1097/coh.0000000000000374

32. Chawla, A., Wang, C., Patton, C., Murray, M., Punekar, Y., de Ruiter, A., Steinhart, C. (2018). A Review of Long-Term Toxicity of Antiretroviral Treatment Regimens and Implications for an Aging Population. Infectious Diseases and Therapy, 7 (2), 183-195. doi: http://doi.org/10.1007/s40121-018-0201-6

33. Weld, E. D., Rana, M. S., Dallas, R. H., Camacho-Gonzalez, A. F., Ryscavage, P., Gaur, A. H. et. al. (2019). Interest of Youth Living With HIV in Long-Acting Antiretrovirals. JAIDS Journal of Acquired Immune Deficiency Syndromes, 80 (2), 190197. doi: http://doi.org/10.1097/qai.0000000000001896

34. Number of new HIV diagnoses. European Health Information Gateway. Available at: https://gateway.euro.who.int/en /indicators/hfa 350-2191-number-of-new-hiv-diagnoses/

35. Fang, J.-Q. (Ed.) (2017). Handbook of Medical Statistics. China: Sun Yat-Sen University, 850

36. Haas, A. D., Zaniewski, E., Anderegg, N., Ford, N., Fox, M. P. et. al. (2018). Retention and mortality on antiretroviral therapy in sub- Saharan Africa: collaborative analyses of HIV treatment programmes. Journal of the International AIDS Society, 21 (2). doi: http://doi.org/10.1002/jia2.25084

37. Hamers, R. L., Rinke de Wit, T. F., Holmes, C. B. (2018). HIV drug resistance in low-income and middle-income countries. The Lancet HIV, 5 (10), e588-e596. doi: http://doi.org/10.1016/s2352-3018(18)30173-5

38. Korzh, I., Romanko, T., Volkova, A., Tereshchenko, L. (2021). The structural analysis of government expenditures on the purchase of antituberculous drugs. ScienceRise: Pharmaceutical Science, 2 (30), 17-25. doi: http://doi.org/10.15587/2519-4852.2021.230028

39. Katz, I. T., Maughan-Brown, B. (2017). Improved life expectancy of people living with HIV: who is left behind? The Lancet HIV, 4 (8), e324-e326. doi: http://doi.org/10.1016/s2352-3018(17)30086-3

40. Marcus, J. L., Chao, C. R., Leyden, W. A., Xu, L., Quesenberry, C. P., Klein, D. B. et. al. (2016). Narrowing the Gap in Life Expectancy Between HIV-Infected and HIV-Uninfected Individuals With Access to Care. JAIDS Journal of Acquired Immune Deficiency Syndromes, 73 (1), 39-46. doi: http://doi.org/10.1097/qai.0000000000001014

41. Mateo-Urdiales, A., Johnson, S., Smith, R., Nachega, J. B., Eshun-Wilson, I. (2019). Rapid initiation of antiretroviral therapy for people living with HIV. Cochrane Database of Systematic Reviews, 6. doi: http://doi.org/10.1002/ 14651858.cd012962.pub2

42. Kotvitska, A., Volkova, A., Korzh, I., Surikova, I. (2021). Comparative analysis of indicators that determine the effectiveness of the implementation of socio-economic determinants of health in Europe and Ukraine. ScienceRise: Pharmaceutical Science, 3 (31), 34-41. doi: http://doi.org/10.15587/2519-4852.2021.235787

Received date 11.12.2021

Accepted date 17.02.2022

Published date 28.02.2022

Valeriia Yefremova, Assistant, Department of Drug Technology, Organization and Economics of Pharmacy, State Establishment «Luhansk State Medical University», Budivelnykiv str., 32, Rubizhne, Ukraine, 93012

Hanna Panfilova, Doctor of Pharmaceutical Sciences, Professor, Department of Organization and Economics of Pharmacy, National University of Pharmacy, Pushkinska str., 53, Kharkiv, Ukraine, 61002

Alla Lebedyn, PhD, Assistant, Department of Organization and Economics of Pharmacy, National University of Pharmacy, Pushkinska str., 53, Kharkiv, Ukraine, 61002

Gennadii Iurchenko, PhD, Associate Professor, Department of Organization and Economics of Pharmacy, National University of Pharmacy, Pushkinska str., 53, Kharkiv, Ukraine, 61002

Oksana Okseniuk, PhD, Assistant, Department of Drug Technology, Organization and Economics of Pharmacy, State Establishment «Luhansk State Medical University», Budivelnykiv str., 32, Rubizhne, Ukraine, 93012

Vitaly Chernukha, PhD, Associate Professor, Department of Organization and Economics of Pharmacy, National University of Pharmacy, Pushkinska str., 53, Kharkiv, Ukraine, 61002

Lyubov Tereshchenko, PhD, Associate Professor, Department of Social Pharmacy, National University of Pharmacy, Pushkinska str., 53, Kharkiv, Ukraine, 61002

Inna Chebernina, Assistant, Department of Pharmacology, Clinical Pharmacology and Clinical Pharmacy, State Establishment «Luhansk State Medical University», Budivelnykiv str., 32, Rubizhne, Ukraine, 93012

*Corresponding author: Hanna Panfilova, e-mail: panf-al@ukr.net 